\title{
Advocacia em Saúde: Prática Cidadã para a Garantia do Direito à Saúde - o Caso do Projeto de Lei Complementar N. 01/2003 ${ }^{(*)}$
}

\author{
HEALTH ADVOCACY : CITIZENSHIP ENSURING THE RIGHT TO HEALTH \\ CASE STUDY OF LAW PROJECT N. 01/2003
}

\author{
Maria Célia Delduque ${ }^{(* *)}$ \\ Priscila Ariede Petinuci Bardal ${ }^{(* * *)}$
}

\section{RESUMO}

A atividade da advocacia em saúde pressupõe a defesa da garantia do pleno desfrute do direito a ela inerente, em contextos localizados. A Constituição de 1988, ao ser emendada em 2000 pela Emenda n. 29, teve alterada a redação do seu $\S 2^{\circ}$ do art. 198, que passou a exigir dos entes federados a vinculação de receitas para as ações e serviços de saúde. O projeto desta lei complementar, exigida constitucionalmente para regulamentar a matéria, tramitou lentamente na Câmara dos Deputados, conseqüência de obstáculos legais e regimentais. Este trabalho tem o objetivo de identificar tais impedimentos ao processo legislativo, em um exercício de advocacia em saúde.

\section{Palavras-chave:}

Advocacia em Saúde; Emenda Constitucional n. 29; Financiamento da Saúde.

(*) Trabalho originalmente apresentado na disciplina Planejamento e Desenvolvimento de Políticas de Saúde: o Papel das Organizações Privadas, Profissionais e Comunitárias, ministrada pela Profa. Dra. Sueli G.Dallari, com a colaboração do Prof. Dr. Fernando Mussa A. Aith e Profa. MSc Silvia Badim Marques, na Faculdade de Saúde Pública da USP, no primeiro semestre de 2007.

${ }^{\left({ }^{*}\right)}$ Advogada, pesquisadora da Fundação Oswaldo Cruz, especialista em Direito Sanitário pela Faculdade de Saúde Pública - Universidade de São Paulo e doutoranda em Saúde Pública na USP. E-mail: <delduque@usp.br>.

$\left.{ }^{* * *}\right)$ Cirurgiã-Dentista, doutoranda em Saúde Pública na USP. E-mail: <priscilabardal@usp.br>. 


\section{ABSTRACT}

The practice of health advocacy presumes the defense of the right to health in particular scenarios. 1988 Constitution has been rewritten by the $29^{\text {th }}$ amendment and the new redaction for the $\S 2^{\text {nd }}$ paragraph of the article 198 now demands that the federative actors must reserve part of its taxes to finance health actions and services. Meanwhile, the project of law to regulate the constitutional orientation is being analyzed by the Congress in a very slowly way due to legal and procedure obstacles. This works is a health advocacy exercice and seeks to identify and discuss the legislatives obstacles to the full realization of the right to health.

\section{Keywords}

Constitutional Amendment n. 29; Health Advocacy; Health Financiaments.

\section{INTRODUÇÃO}

A Constituição de 1988 que reconheceu o direito à saúde para todos também vinculou uma cesta de tributos ao seu financiamento. Embora o direito à saúde tenha sido reconhecido em nosso ordenamento jurídico, sua realização está grandemente condicionada ao financiamento das ações e serviços de saúde.

Ocorre que o financiamento do setor sanitário está incluído em um cenário de incertezas, impedindo a plena concretização do direito à saúde. Ainda resta indefinida uma base suficiente e definitiva de financiamento para o setor de forma a garantir a realização plena das ações e serviços públicos de saúde. Por isso, existe absoluto consenso sobre a necessidade de conferir uma estabilidade ao financiamento público da saúde e esta preocupação perpassa pelo Congresso Nacional.

É fato que o modelo de financiamento do Sistema Único de Saúde (SUS) foi substancialmente melhorado com o advento da Emenda Constitucional n. 29, de 2000; contudo, esse aperfeiçoamento ainda não significa necessariamente uma resposta satisfatória à crescente demanda por ações e serviços no campo da saúde pública ${ }^{(1)}$.

Após a aprovação, pelo Legislativo, da Emenda n. 29 foi apresentado à Câmara dos Deputados o Projeto de Lei Complementar n. 1, de 2003, para regulamentar esta emenda.

(1) LAZZARI, J. B. Fontes de financiamento do Sistema Único de Saúde. Revista de Direito Sanitário, São Paulo, v. 4, n. 1, p. 75-84, mar. 2003. 
Sua tramitação enseja um olhar mais atento da sociedade, posto que pode significar, além de percalços regimentais, uma verdadeira obstrução a sua aprovação em lei.

Por outro lado, a história mostra que o reconhecimento de direitos sociais e sua realização ocorrem precedidos de ações transformadoras, que alteram a estrutura estabelecida. Tal pode acontecer em função de interesses universais ou em questões locais. O que salta aos olhos nestes movimentos bem-sucedidos é a organização das pessoas envolvidas, que fazem uso de instrumentos de persuasão eficientes e, principalmente, apresentam pleitos legítimos. Assim, é o exercício da advocacia.

Quando se pensa em advocacia, imediatamente vem à mente a idéia daquele que detém um conhecimento técnico-forense que poderá ser posto a serviço de um interesse. No entanto, a advocacia pode ser mais ampla para significar a reivindicação de um direito ainda não reconhecido ou não materialmente garantido. Para isso, o advogado não precisa ser o bacharel legalmente habilitado, mas todo aquele que, comprometido com a causa a ser defendida, lançará mão de técnicas, processos, estratégias para se atingir o pretendido.

Dallari et alli(2) conceituam a advocacia como "um processo que utiliza conjunto de estratégias políticas visando promover direitos não respeitados, através de meios legais e éticos, a favor de grupos sociais desfavorecidos ou oprimidos".

Vale ressaltar que a essência deste processo é a busca de garantias e a efetivação do direito e dos instrumentos inerentes ao bem jurídico que se está defendendo.

A saúde para todos, por exemplo, é um direito estabelecido no ordenamento jurídico brasileiro, e sua reivindicação é legitimada pela estreita ligação com a própria noção de vida.

Ao considerar o processo de advocacia em saúde, é necessário pontuar aspectos para o reconhecimento de um direito. Em primeiro lugar é preciso que ele seja reconhecido formalmente. É imprescindível também que sejam explicitadas as formas para se estabelecer a garantia desse direito mediante instrumentos pelos quais ele será concretizado. Além disso, é necessária a busca da efetivação das garantias reconhecidas. Deste modo, os direitos, para que sejam assim definidos, passam pelo seu reconhecimento institucional, positivação de garantias para o seu pleno exercício e instrumentos para a sua efetivação.

(2) DALLARI, Sueli G. et al. Advocacia em saúde no Brasil contemporâneo. Revista de Saúde Pública, São Paulo, v. 30, n. 6, p. 592-601, 1996. 
Da confluência dessas duas realidades - a regulamentação da Emenda Constitucuinal n. 29, que garantirá um financiamento mais perene para o setor da saúde, e o processo de advocacia em saúde - surge o objetivo do presente artigo, que não esgotará o tema, visto sua abrangência e que pretende: estudar a tramitação legislativa do Projeto de Lei Complementar n. 1, de 2003, que regulamenta o § 3ํำ do art. 198 da Constituição Federal, a fim de conhecer o cenário legislativo em que se encontra, analisar os aspectos formais nucleares do problema de sua aprovação, bem como os atores e obstáculos normativos envolvidos, para obter sua transformação em lei.

\section{O RECONHECIMENTO E A CONQUISTA DO DIREITO À SAÚDE}

A Constituição Federal de 1988 considerou a saúde como direito de todos e dever do Estado. Foi a primeira vez na história constitucional brasileira que a saúde foi prevista como um direito. Substituiu-se um modelo baseado no princípio contributivo e centralizado por outro de direito lega/(3) e universal de acesso gratuito a ações e serviços de saúde em todos os níveis de complexidade, organizado de modo hierarquizado e descentralizado.

O Sistema Nacional de Saúde implementado no país entre 1964 e 1974 foi marcado por uma lógica centralizadora com dominante traço mercantilista. Escore/(4) nos conta que a saúde pública tornou-se uma máquina ineficiente e conservadora, cuja atuação restringia-se a campanhas de baixa eficiência.

O caráter assimétrico, heterogêneo e fragmentário do modelo engendrado no período deu ensejo a que se acirrasse a politização dos debates sobre as condições de saúde da sociedade brasileira e fizesse nascer o projeto de Reforma Sanitária, no berço da VIII Conferência Nacional de Saúde, em março de 1986, que orientou, de maneira determinada, a construção constitucional do direito à saúde, em 1988.

O êxito do movimento sanitário brasileiro na inscrição da saúde como direito no texto constitucional durante os trabalhos da Assembléia Nacional Constituinte deu-se porque, associado às muitas frentes de batalha abertas para a direita que pulverizou seus quadros parlamentares entre as diversas comissões, o movimento sanitário atuava coeso com seus aliados ${ }^{(5)}$.

(3) ARRETCHE, Marta. Financiamento federal e gestão local de políticas sociais: o difícil equilíbrio entre regulação, responsabilidade e autonomia. Revista Ciência e Saúde Coletiva, Rio de Janeiro, v. 8, n. 2, p. 331-345, 2003.

(4) ESCOREL,Sarah; NASCIMENTO, Dilene R.; EDLER, Flavio C. As origens da reforma sanitária e do SUS. In: SAÚDE e democracia: história e perspectivas do SUS. Rio de Janeiro: Fiocruz, 2005. p. 59-81.

(5) GOMES, Maria Angélica. Equidade e universalidade do direito à saúde: representação de interesses no Congresso Nacional, 1987-1990. Dissertação (Mestrado) Faculdade de Estudos Sociais Aplicados, Universidade de Brasília, 1996. Mimeo. 
A área da saúde tinha uma proposta discutida, legitimada e completa que serviu como marco fundamental da definição da saúde como prioridade do Estado e direito de todos. Estava assim, reconhecido institucionalmente o direito à saúde no Brasil.

\section{A POSITIVAÇÃO DA GARANTIA DO DIREITO À SAÚDE PELO FINANCIAMENTO DAS AÇÕES E SERVIÇOS DE SAÚDE}

Um direito não pode ser um corpo sem alma ou apenas um pedaço de papel. Um direito, formalmente considerado, deve ter sua realização material, a garantia de seu pleno desfrute. Assim, na esteira da garantia do direito à saúde, a Lei Maior estabeleceu, dentre outras, a garantia do financiamento das ações e serviços de saúde, porque como em outras políticas públicas, o financiamento é um poderoso indutor de estratégias e ações.

Tem razão $A i t h^{(6)}$ quando assevera que a discussão sobre o financiamento das ações e serviços públicos de saúde é um tema pouco explorado no Brasil e que para a realização do direito à saúde, tão essencial ao ser humano, é necessário que se destinem recursos financeiros a fim de que as ações e serviços de saúde cheguem adequadamente a quem deles necessita.

A Constituição, ao ser promulgada, continha no art. 55 do Ato das Disposições Constitucionais Transitórias (ADCT), a disposição de que, até a aprovação da Lei de Diretrizes Orçamentárias (LDO), no mínimo, 30\% do Orçamento da Seguridade Social seria destinado ao setor saúde. Mas, como asseveram Reis, Ribeiro e Piola(7) a falta de clareza no estabelecimento da repartição dessas receitas, fez gerar uma competição entre as ações de saúde e previdência. Prevaleciam, certamente, para esta última, as melhores fatias do montante arrecadado, em face dos benefícios previdenciários legalmente definidos. Para estes, os gastos dificilmente eram retraídos, cabendo às demais áreas da seguridade a árdua tarefa de condicionar suas ações a constantes ajustes orçamentários.

Outras tentativas foram agregadas ao frágil dispositivo do financiamento da saúde, sem, contudo, obter a eficácia pretendida pelo setor, deixando esta área, a cada ano, ao sabor de patamares inadequados de recursos, prolongando-se a crise crônica de financiamento.

Para a manutenção de um sistema baseado no financiamento público e de cobertura universal, o estabelecimento de fontes estáveis de financia-

(6) AITH, Fernando Mussa A. O financiamento da Saúde. Revista de Direito Sanitário, São Paulo, v. 4, n. 1, p. 60-62, mar. 2003.

(7) REIS, Carlos Octávio O.; RIBEIRO, José Aparecido C.; PIOLA, Sergio F. Financiamento das políticas sociais nos anos 1990: o caso do Ministério da Saúde. Brasília: IPEA, 2001. 
mento tornou-se essencial, relata-nos Faveret ${ }^{(8)}$. A partir deste reconhecimento, surgiram várias propostas de emendas à Constituição (PEC) visando garantir tais recursos. Por fim, em 2000, pela EC n. 29/00, foi dada nova redação ao $\S 2^{\circ}$ do art. 198, garantindo que o financiamento da saúde deve ter volume e regularidade adequados e que a União, Estados e Municípios devem vincular patamares mínimos de recursos, a fim de garantir o direito à saúde.

Isto parece bem trivial; no entanto, não é.

A EC n. 29/00 não define, por exemplo, o que entende por ações e serviços públicos de saúde, se serão somente os dispêndios realizados por intermédio do Ministério da Saúde ou se deverão ser levados em conta os demais gastos correlatos, como por exemplo, os montantes aplicados em hospitais universitários pelo Ministério da Educação ou a manutenção dos serviços de saúde do Distrito Federal. Estas dúvidas e algumas interpretações controversas da emenda, quanto à definição do que são ações e serviços de saúde mostraram a urgência de um Projeto de Lei Complementar (PLP) que desse um entendimento definitivo à questão.

Assim, a regulamentação deste ditame constitucional ficou a cargo de um PLP a ser formulado por uma das Casas do Congresso. Todavia, até a data da redação deste trabalho, a lei complementar responsável pela garantia do financiamento do setor da saúde, ainda não fora aprovada e, por isso, o contido na emenda constitucional não poderá ser plenamente aplicável.

O problema colocado, portanto, é a dificuldade da garantia do direito à saúde por intermédio do financiamento das ações e serviços de saúde, consubstanciada na aprovação de um projeto de lei complementar que tramita no Congresso Nacional há 4 anos $^{(9)}$.

\section{EFETIVAÇÃO DA GARANTIA DO FINANCIAMENTO DA SAÚDE - O EXERCÍCIO DO ADVOCACY EM SAÚDE}

A participação social no Brasil ainda é bastante incipiente. No campo da saúde, embora assegurada constitucionalmente a participação popular nas políticas públicas sanitárias, não há evidências "maduras" dessa experiência democrática na realidade brasileira.

(8) FAVERET, Ana C. S. C. A vinculação constitucional de recursos para a saúde: avanços, entraves e perspectivas. Revista Ciência \& Saúde Coletiva, Rio de Janeiro, v. 8 n. 2, p. 371-378, 2003.

(9) Proposições desse regulamento também foram apresentadas ao Senado Federal: o Projeto de Lei do Senado n. 35, de 2002, de autoria do Senador Tião Viana (PT-AC), acabou arquivado por razões regimentais no final da última legislatura, e dois outros, apresentados na atual legislatura, não chegaram sequer a serem apreciados na primeira comissão (CCJ) — o que deu razão ao arquivamento. 
A participação popular da qual se fala não se restringe à formação dos conselhos de saúde ou às conferências de saúde, mas, sim, a uma participação mais ampla, aquela inerente ao cidadão pleno que acompanha, participa, fica por dentro, cobra e exige. Até mesmo as entidades associativas não têm demonstrado a capacidade de desenvolver um núcleo militante para atuar de modo organizado e estratégico, com os objetivos de obter para seus associados a prestação de um serviço de saúde, a obrigatoriedade de observação de uma norma ou de pressionar seus representantes por leis mais justas.

Advogar uma causa é interceder em favor desta mesma causa, usando as ferramentas da persuasão, argumentação e convencimento. Então, a advocacia da qual se fala significa a promoção de meios para instrumentalizar cidadãos organizados, para que sejam capazes de desenvolver a cidadania que Ihes habilita a participar da vida social, das decisões que lhes afeta, de serem ouvidos e, especialmente, de influenciarem nas políticas públicas e decisões de Estado.

Advocacia em Saúde é isso: um processo de fortalecimento de cidadãos ou grupos de cidadãos para o exercício reivindicatório de seu direito à saúde, quando não usufruído plenamente, junto às instâncias estatais e não-estatais, realizado por instrumentos de persuasão e convencimento. Como dito, advogar em saúde significa a reivindicação pelo direito à saúde, de forma específica.

Este processo - advocacia em saúde - cabe no que se refere à aprovação da PLP n. 01/03 no Congresso Nacional, porque como explica Dallari et alli(10), "a advocacia não se ocupa do direito à saúde propriamente dito, mas na sua realização em contextos localizados". Se o direito à saúde perpassa pela garantia do financiamento de suas ações e serviços, "a atuação do advogado em saúde nos casos em que o recurso financeiro é condição para a implementação de uma política de saúde é extremamente necessária"(11). Assim, pode chamar para si a tarefa de acompanhar, compreender e agir em favor da aprovação da proposição referida.

Em advocacia, ensina-nos Barber-Madden(12), utilizam-se quatro processos básicos:

a) identificação de um problema particular e a documentação a ele pertinente;

(10) DALLARI, Sueli G. et al., op. cit., p. 597.

(11) Id. Ibid., p. 600.

(12) BARBER-MADDEN, Rosemary. La abogacia en salud publica. In: INFORMES Técnicos n. $10-E l$ derecho a la salud en la nueva Constitución brasileña. Washington: OPAS, 1992. p.19 
b) avaliação da situação política em que se analisa minuciosamente o problema a fim de determinar a elaboração de estratégia;

c) formulação de estratégias para intervir no processo decisório;

d) seguimento contínuo da situação para tratar de garantir que o setor escolhido como objetivo responda às necessidades sociais.

Assim, como parte do processo de advocacia em saúde, pretende-se conhecer o histórico da tramitação do Projeto de Lei Complementar n. 1, de 2003, na Câmara dos Deputados, desde sua original proposição, parlamentares envolvidos na relatoria, apresentação de emendas, discussões e votações nas Comissões Parlamentares Permanentes, até sua submissão ao Plenário, sistematizando-se as informações a fim de serem apreciadas uniformemente.

Para a obtenção de informações, utilizou-se a página na internet da Câmara dos Deputados. Além disso, a fim de que o enfoque pretendido fosse dado de forma contextualizada, realizou-se um busca bibliográfica relacionada ao aspecto do financiamento da saúde no Brasil, selecionando-se artigos pertinentes ao tema.

\section{ENTENDENDO O CENÁRIO LEGISLATIVO DA TRAMITAÇÃO DO PROJETO DE LEI COMPLEMENTAR N. 1, DE 2003}

Em 18 de fevereiro de 2003, tão logo iniciada a 52ª legislatura, o Deputado Roberto Gouveia (PT-SP) apresentou à Câmara dos Deputados, um projeto de lei complementar em atendimento ao que dispunha o § 3으 do art. 198 da Constituição Federal com sua redação dada pela Emenda à Constituição n. 29, de 2000 .

Os projetos de lei complementar seguem uma tramitação especial, como as Propostas de Emenda à Constituição (PEC). De acordo com o Regimento Interno da Câmara dos Deputados (RICD), em seu art. 148:

As proposições em tramitação na Câmara são subordinadas, na sua apreciação, a turno único, excetuadas as propostas de emenda à Constituição, os projetos de lei complementar e os demais casos expressos neste Regimento.

Ficam ainda submetidos à regra do art. 69 da CF/88 que dispõe que "As leis complementares serão aprovadas por maioria absoluta".

Percebe-se, então, que a tramitação de um PLP na Câmara dos Deputados e no Senado Federal será, em princípio, mais lenta que a de um projeto de lei ordinária, em vista do especial trâmite e disposições peculiares para sua votação e aprovação. $\mathrm{CF} / 88$ :

A proposição de um projeto de lei complementar, segundo o art. 61 da 
[...] cabe a qualquer membro ou Comissão da Câmara dos Deputados, do Senado Federal ou do Congresso Nacional, ao Presidente da República, ao Supremo Tribunal Federal, aos Tribunais Superiores, ao Procurador-Geral da República e aos cidadãos, na forma e nos casos previstos nesta Constituição.

Enquanto o projeto tramitava, formou-se um grupo intersetorial temático para discutir a regulamentação da EC n. 29/00. Compôs o grupo, além de parlamentares constituintes das comissões citadas, representantes do Ministério da Saúde, do Conselho dos Secretários Estaduais de Saúde (CONASS), do Conselho dos Secretários Municipais de Saúde (CONASEMS), do Conselho Nacional de Saúde, do Ministério Público Federal, a Organização Pan-Americana da Saúde (OPAS), o Instituto de Pesquisa Econômica Aplicada (IPEA), o Instituto Brasileiro de Geografia e Estatística (IBGE), o ConseIho Federal de Contabilidade, Fundação Getúlio Vargas e Banco do Brasil. Esse grupo elaborou o documento intitulado Parâmetros Consensuais sobre a Implementação e a Regulamentação da Emenda Constitucional n. 29, que serviu de base para que o Conselho Nacional de Saúde aprovasse a Resolução n. 322, de 8 de maio de 2003, a qual apontou algumas diretrizes para a aplicação da Emenda Constitucional n. 29, enquanto não fosse editada a Lei Complementar.

Além dessa resolução, outro instrumento normativo também contribuiu para a operacionalização do financiamento da saúde no Brasil: a Portaria n. 2.047, editada pelo Ministério da Saúde em 5 de novembro de 2002.

Os dois instrumentos visam, em suma, estabelecer diretrizes para a aplicação da EC n. 29/00, esclarecendo e detalhando basicamente os seguintes aspectos conceituais e operacionais: a) a base vinculável dos Estados, Distrito Federal e Municípios; b) as regras de cálculo dos recursos mínimos a serem aplicados em saúde pelos entes federados; c) a definição dos gastos que devem ser incluídos como "ações e serviços de saúde" para efeitos da EC n. 29/00; e d) os instrumentos de acompanhamento, fiscalização e controle ${ }^{(13)}$. $O$ fato é que ainda hoje, e na ausência de uma disposição legal oriunda do Congresso Nacional, a Resolução n. 322, de 2003, é o documento de orientação da aplicação da EC n. 29/00(14).

O PLP n. 1/03 tramitou na Câmara dos Deputados, tendo recebido parecer favorável das três comissões parlamentares às quais foi submetido: Comissão de Constituição e Justiça e Cidadania (CCJC); Comissão de Seguridade Social e Família (CSSF); e Comissão de Finanças e Tributação (CFT).

(13) SAMBIASE, A. G. F. Aspectos legais da Emenda Constitucional n. 29/00. Revista de Direito Sanitário, São Paulo, v. 4, n. 1, p. 63-74, mar. 2003.

(14) O documento não tem acolhida universal e é, freqüentemente, descumprido ou desconsiderado. 
Vale a pena ressaltar que as comissões permanentes da Câmara dos Deputados são organizadas por temas. Deste modo, sobre cada assunto específico tratado na proposição legislativa, a comissão temática correspondente deverá se manifestar. A saúde, por exemplo, tem na Comissão de Seguridade Social e Família (CSSF) o seu locus preferencial. A Comissão de Constituição e Justiça e Cidadania, apresenta o diferencial de apreciar, quanto à constitucionalidade, juridicidade e técnica legislativa todos os projetos de lei, sem exceção.

Um projeto de lei, em sua tramitação legislativa, garantia do vital processo democrático de construção das leis, pode receber emendas parlamentares. O PLP n. 1/03 recebeu várias emendas, tendo sido a principal delas aprovada em forma de substitutivo, na CSSF.

Uma emenda é uma espécie de proposição, acessória de outra, que altera, suprime, modifica, adiciona algo na proposição emendada. De acordo com o art. 118 do RICD, as emendas podem ser supressivas, aglutinativas, substitutivas, modificativas ou aditivas, sendo que no $\S 4^{\circ}$ é disposto:

Emenda substitutiva é a apresentada como sucedânea a parte de outra proposição, denominando-se "substitutivo" quando a alterar, substancial ou formalmente, em seu conjunto; considera-se formal a alteração que vise exclusivamente ao aperfeiçoamento da técnica legislativa.

Em 2004, dois outros projetos tratando da mesma matéria foram apresentados à Câmara dos Deputados e, em conformidade com o RICD, foram apensados ao primeiro, (Quadro I). Deste apensamento, no entanto, surgiu a necessidade de oferecer-se um substitutivo ao projeto, visto ter as três proposições aspectos irreconciliáveis como, por exemplo, o percentual do montante de recursos estabelecido para a União — único ente para o qual a EC n. 29/00 não definiu uma base vinculável para o período após 2004 - deixando expressamente a tarefa para a lei complementar. O PLP n. 1, de 2003, destinava 11,5\% sobre o total de receitas da União advindas de impostos e contribuições, descontadas as transferências constitucionais, enquanto o PLP n. 181, de 2004, propunha $3 \%$ do valor nominal do Produto Interno Bruto (PIB). O terceiro projeto não tratou dessa questão. A emenda passou a ser conhecida como Substitutivo Guilherme Menezes, nome do deputado relator da matéria na CSSF.

Quadro I - Autores de proposições sobre a regulamentação da Emenda n. 29/00

\begin{tabular}{|c|c|c|c|c|}
\hline Qualificação & Nome & Partido/Estado & Profissão & Proposição \\
\hline Propositor & Roberto Gouveia & PT/SP & Médico & PLP n. 1/2003 \\
\hline Propositor & Geraldo Resende & PPS/RS & Médico & PLP n. 159/2004 \\
\hline Propositor & Rafael Guerra & PSDB/MG & Médico & PLP n. 181/2004 \\
\hline
\end{tabular}

Fonte: Homepage da Câmara dos Deputados (www.camara.gov.br). 
Os Projetos ns. 159/04 e 181/04 foram apensados ao PLP n. 1/2003

Aprovado nas Comissões, o substitutivo ao PLP 1/2003 seguiu para o Plenário da Câmara dos Deputados, a fim de ser apreciado naquela instância, com a possibilidade de receber emendas de plenário, e submeter-se a dois turnos de votação.

A matéria foi debatida em primeiro turno no Plenário. Porém, houve uma suspensão da discussão, pelo fato de que não foram aprovadas Medidas Provisórias, ainda não votadas, sobrestando o bom andamento da votação pretendida. Por exemplo, em 11 de abril de 2006, o debate foi suspenso porque a Medida Provisória n. 281 não havia sido apreciada terminativamente. Em 25 de abril daquele mesmo ano, o óbice da apreciação ficou a cargo da não deliberação da Medida Provisória n. 275-5 e, em uma terceira oportunidade, idêntico obstáculo ocorreu em relação à Medida Provisória 275.

Para melhor compreensão cabem aqui dois esclarecimentos. O primeiro é sobre a pauta da Ordem do Dia da Câmara dos Deputados e o outro é sobre o trancamento desta pauta pela não votação de uma medida provisória.

As sessões plenárias da Câmara dos Deputados estão regimentalmente previstas no art. 81 do RICD. São as chamadas Ordens do Dia. É o momento em que se encerram os pronunciamentos parlamentares (pequeno e grande expediente) e dá-se início ao debate e votação de matéria legislativa.

Às onze ou às dezesseis horas, conforme o caso, passar-se-á a tratar da matéria destinada à Ordem do Dia, sendo previamente verificado o número de Deputados presentes no recinto do Plenário, através do sistema eletrônico, para o mesmo efeito do que prescreve o § 5얼 deste artigo.

A Ordem do Dia é organizada pelo Presidente da Casa Legislativa correspondente, ouvido o Colégio de Líderes ${ }^{(15)}$.

Já as medidas provisórias devem ter sua apreciação pelo Congresso Nacional em prazo constitucionalmente estabelecido no $\S 6^{\circ}$ do art. 62 , sob pena de trancarem a pauta de votação da Casa Legislativa onde tramitam:

Se a medida provisória não for apreciada em até quarenta e cinco dias contados de sua publicação, entrará em regime de urgência, subseqüentemente, em cada uma das Casas do Congresso Nacional, ficando sobrestadas, até que se ultime a votação, todas as demais deliberações legislativas da Casa em que estiver tramitando.

Mesmo já tendo recebido parecer favorável das três comissões parlamentares pelas quais foi submetida, a aprovação do Projeto de Lei Comple-

(15) Os Deputados são agrupados por representações partidárias ou de Blocos Parlamentares, cabendo-lhes escolher o Líder quando a representação for igual ou superior a um centésimo da composição da Câmara. 
mentar n. 1/03 no Congresso Nacional, apresenta obstáculos legislativos a serem superados, sem falar, certamente, nos obstáculos políticos que envolvem a questão e que não estão discutidos no âmbito deste trabalho por fugirIhe ao seu escopo.

A lenta tramitação do projeto (afinal não há um prazo máximo definido sobre as votações de projetos de lei), embora tenha dado ensejo a seu aprimoramento por meio das emendas a ele incorporadas, propiciou também um retardo na sua aprovação. Além disso, perpassa por uma decisão eminentemente política a inserção do projeto na Ordem do Dia, posto que o Presidente da Câmara deve ouvir o Colégio de Líderes para organizar a pauta.

O trancamento da pauta de votações em face de retardo na apreciação de medidas provisórias representa, de fato, um forte obstáculo à apreciação e votação da matéria do projeto analisado.

Alguns deputados têm usado a tribuna e pleiteado, por meio de requerimentos de urgência e de inclusão do PLP 1/03 na pauta de votação, a aceleração do processo de sua apreciação e votação. Embora bem intencionados, a pequena expressão política em nível nacional desses parlamentares não faz seus pronunciamentos e súplicas serem ouvidos pelas lideranças partidárias daquela Casa Legislativa (vide Quadro II para detalhamento).

Quadro II - Parlamentares que interferiram favoravelmente na
tramitação do PLP 01/03, no Plenário da Câmara dos Deputados

\begin{tabular}{|l|l|c|c|c|}
\hline Qualificação & \multicolumn{1}{|c|}{ Nome } & Partido/Estado & Profissão & Proposição \\
\hline $\begin{array}{l}\text { Requerimento } \\
\text { n. 3.687/06 }\end{array}$ & $\begin{array}{l}\text { Dimas } \\
\text { Ramalho }\end{array}$ & PPS/SP & Delegado & $\begin{array}{c}\text { Pedido de urgên- } \\
\text { cia na votação }\end{array}$ \\
\hline $\begin{array}{l}\text { Requerimento } \\
\text { n. 317/07 }\end{array}$ & $\begin{array}{l}\text { Vital do } \\
\text { Rego Filho }\end{array}$ & PMDB/PB & Médico & $\begin{array}{c}\text { Inclusão na } \\
\text { ordem do dia }\end{array}$ \\
\hline $\begin{array}{l}\text { Requerimento } \\
\text { n. 887/07 }\end{array}$ & $\begin{array}{l}\text { Acélio } \\
\text { Casagrande }\end{array}$ & PMDB/SC & & $\begin{array}{c}\text { Inclusão na } \\
\text { ordem do dia }\end{array}$ \\
\hline $\begin{array}{l}\text { Requerimento } \\
\text { n. 905/07 }\end{array}$ & $\begin{array}{l}\text { Clodovil } \\
\text { Hernandes }\end{array}$ & PTC/SP & Comunicador & $\begin{array}{c}\text { Inclusão na } \\
\text { ordem do dia }\end{array}$ \\
\hline $\begin{array}{l}\text { Requerimento } \\
\text { n. 922/07 }\end{array}$ & $\begin{array}{l}\text { Acélio } \\
\text { Casagrande }\end{array}$ & PMDB/SC & & $\begin{array}{c}\text { Pedido de } \\
\text { urgência }\end{array}$ \\
\hline $\begin{array}{l}\text { Requerimento } \\
\text { n. 1.432/07 }\end{array}$ & $\begin{array}{l}\text { Renato } \\
\text { Molling }\end{array}$ & PP/RS & Administrador & $\begin{array}{c}\text { Inclusão na } \\
\text { ordem do dia }\end{array}$ \\
\hline $\begin{array}{l}\text { Requerimento } \\
\text { n. 1.553/07 }\end{array}$ & $\begin{array}{l}\text { Maria do } \\
\text { Rosário }\end{array}$ & PT/RS & Professora & $\begin{array}{c}\text { Inclusão na } \\
\text { ordem do dia }\end{array}$ \\
\hline
\end{tabular}

Fonte: Homepage da Câmara dos Deputados (www.camara.gov.br). 
Outrossim, o texto legislativo da proposição também representa um obstáculo. Sua abrangência dificulta o entendimento de uma maioria de atores que comumente organizam-se para acompanhar proposições como a estudada, e informações de conteúdo técnico afastam do interesse uma representativa parcela da população, que poderia funcionar como grupo de pressão.

Adicionalmente, pode-se especular que, por existir a Resolução n. 322/03, os legisladores utilizem este instrumento normativo, como justificativa para a pouca celeridade conferida à votação do PLP n. 1/03.

\section{O SENADO ENTRA EM CENA}

Em 20 de março de 2007, o Senador Tião Viana (PT-AC) apresentou um projeto de lei complementar (PLS n. 121/07) que dispõe sobre os valores mínimos a serem aplicados anualmente por Estados, Distrito Federal, Municípios e União em ações e serviços públicos de saúde; os critérios de rateio dos recursos de transferências para a saúde e as normas de fiscalização, avaliação e controle das despesas com saúde nas três esferas de governo. Tratava-se de um texto muito semelhante àquele do Deputado Roberto Gouveia.

O PLS n. 121/07 estabelece a correção do orçamento da saúde em $10 \%$ das receitas brutas e estipula que $25 \%$ dos recursos devem ser distribuídos segundo critério baseado no perfil epidemiológico e demográfico de cada Estado, além da estrutura da rede de saúde, em conformidade com a Lei 8.080/90.

Aprovado na Comissão de Constituição, Justiça e Cidadania (CCJ), seguiu para a Comissão de Assuntos Econômicos (CAE) e atualmente se encontra em processo de tramitação na Comissão de Assuntos Sociais (CAS). $\mathrm{Na} \mathrm{CAE}$, o projeto foi aprovado graças a uma emenda apaziguadora entre a pressão do Movimento Sanitário, da Frente Parlamentar da Saúde ${ }^{(16)}$ e do Ministério da Saúde e a resistência da equipe econômica do governo, representada pela proposta do Senador Francisco Dornelles (PP-RJ). O dispositivo prevê que $25 \%$ das verbas destinadas aos Estados deverão ser distribuídas de acordo com o modelo adotado pelo Fundo de Participação dos Estados, ou seja, inversamente proporcional à renda per capita de seus habitantes um mecanismo de distribuição de receitas: assim, quanto mais pobre o Estado, maior o valor repassado.

A alteração proposta pela emenda modifica a forma de correção do orçamento da saúde pela variação do Produto Interno Bruto dos últimos dois

(16) A Frente Parlamentar da Saúde foi criada em 1993 na Câmara dos Deputados. A FPS reúne 237 deputados e 23 senadores. 
anos. Além disso, foram incluídas como ações específicas de saúde, as despesas com aposentados e pensionistas da área e com saneamento básico em municípios de até 50 mil habitantes.

\section{Quadro III — Tramitação do PLS n. 121/07 nas Comissões do Senado Federal}

\begin{tabular}{|c|c|c|}
\hline Comissão & Situação & Relator \\
\hline $\begin{array}{c}\text { CCJ - Comissão de } \\
\text { Constituição, Justiça e e } \\
\text { Cidadania }\end{array}$ & $\begin{array}{c}\text { Parecer oferecido em } \\
05.09 .2007 \text { - Aprovado }\end{array}$ & $\begin{array}{c}\text { Senador Antônio } \\
\text { Carlos Valadares } \\
\text { (PSB-SE) }\end{array}$ \\
\hline $\begin{array}{c}\text { CAE - Comissão de } \\
\text { Assuntos Econômicos }\end{array}$ & $\begin{array}{c}\text { Parecer oferecido em } \\
02.10 .2007 \text {-Aprovado }\end{array}$ & $\begin{array}{c}\text { Senadora Patrícia } \\
\text { Saboya (PDT-CE) }\end{array}$ \\
\hline $\begin{array}{c}\text { CAS - Comissão de } \\
\text { Assuntos Sociais }\end{array}$ & $\begin{array}{c}\text { Matéria encaminhada à } \\
\text { relatoria em 03.10.2007 }\end{array}$ & $\begin{array}{c}\text { Senador Augusto } \\
\text { Botelho (PT-RR) }\end{array}$ \\
\hline
\end{tabular}

Fonte: Homepage do Senado Federal (www.senado.gov.br).

O episódio da aprovação na CAE do projeto do Senador Tião Viana, com as alterações promovidas pela emenda do Senador Francisco Dornelles, desencadeou um movimento em defesa da saúde e pela aprovação da proposta em tramitação na Câmara, até então em suplicante espera por um espaço na Ordem do Dia do Plenário daquela casa legislativa.

\section{A PRÁTICA DA ADVOCACIA EM SAÚDE: APROVAÇÃO DO PLP $1 / 03$}

A Frente Parlamentar da Saúde, após a aprovação do projeto de iniciativa do Senado Federal, posicionou-se no sentido de alertar a base aliada e o movimento sanitarista brasileiro sobre a forma como o texto fora aprovado, o que certamente causaria uma diminuição dos recursos destinados à saúde além de estabelecerem-se gastos diversos como se de saúde fossem. A estratégia, segundo o Presidente da Frente Parlamentar da Saúde, deputado Darcísio Perondi (PMDB-RS), foi a de pressionar ainda mais o presidente da Câmara, deputado Arlindo Chinaglia (PT-SP), para que ele colocasse o PLP n. 1/03 na pauta de votações do Plenário da Câmara, com a rapidez que o caso merecia, a fim de frustrar a tentativa do Senado Federal em aprovar em seu plenário o projeto indesejado pelo setor da saúde. 
A Frente Parlamentar da Saúde em uma bem-sucedida ação de advocacia em saúde, atuou em muitas frentes. Conclamou a sociedade para a causa da aprovação do substitutivo ao projeto PLP 1/03, veiculando nos principais jornais e mídia televisiva os embates parlamentares sobre o tema. De igual modo, atuava internamente, nos corredores da Câmara, com a campanha: "Parlamentares: salvem a saúde !!!" Ainda atuou angariando votos e apoios e articulando-se com o Palácio do Planalto, que acabou recuando em face do forte lobby da saúde.

O texto aprovado na Câmara foi uma vitória para o setor da saúde, embora mantivesse a correção do orçamento da saúde pela variação do Produto Interno Bruto (PIB) Nominal, desejo da equipe econômica do governo, houve a negociação de um aumento escalonado já a partir de 2008 , com $8,5 \%$ da receita da União, o que equivale a um acréscimo de $\mathrm{R} \$ 12$ milhões ao orçamento da pasta de $\mathrm{R} \$ 47$ bilhões já garantidos ${ }^{(17)}$.

\section{CONCLUSÃO}

Embora se reconheça que os obstáculos legais e regimentais atrasaram, sobremaneira, a aprovação do PLP n. 1/03 na Câmara dos Deputados, certamente o mais importante obstáculo esteve na esfera política e merece um olhar mais atento dos eleitores engajados na luta por uma fonte de financiamento mais perene para as ações e serviços de saúde.

A proposta surgida no Senado Federal, especialmente agregada da emenda oferecida na CAE, tornou a EC n. 29/00, e o ideal daqueles que por ela lutaram, um sonho distante; mas, produziu nos engajados na luta pela veiculação de receitas para a saúde, um fôlego para mais uma batalha. Movimentação de parlamentares favoráveis à aprovação da regulamentação da Emenda Constitucional nos moldes que favoreçam um maior aporte de recursos regulares para o setor da saúde, ganhou a mídia e despertou o debate na sociedade em um espetacular exercício de iluminar a causa, atrair simpatias e advogar pela saúde. Espera-se que os próximos capítulos sejam escritos com tintas sanitaristas e que por fim, a saúde, ganhe essa guerra.

\section{REFERÊNCIAS BIBLIOGRÁFICAS}

AITH, Fernando Mussa A. O financiamento da Saúde. Revista de Direito Sanitário, São Paulo, v. 4, n. 1, p. 60-62, mar. 2003.

ARRETCHE, Marta. Financiamento federal e gestão local de políticas sociais: o difícil equilíbrio entre regulação, responsabilidade e autonomia. Revista Ciência e Saúde Coletiva, Rio de Janeiro, v. 8, n. 2, p. 331-345, 2003.

(17) Informações obtidas da Frente Parlamentar da Saúde por e-mail. 
BARBER-MADDEN, Rosemary. La abogacia en salud publica. In: INFORMES Técnicos n. 10 - El derecho a la salud en la nueva Constitución brasileña. Washington: OPAS, 1992.

BRASIL. Câmara dos Deputados. Disponível em: <www.camara.gov.br>. Acesso em: 18 maio 2007.

Federal, 2007.

Constituição da República Federativa do Brasil. Brasília: Senado

Frente Parlamentar da Saúde. Comissão do Senado aprova texto ruim para a saúde. Brasília, 3 de outubro de 2007. Gabinete do Deputado Darcísio Perondi.

Regimento Interno da Câmara dos Deputados. Brasília: Câmara dos Deputados, 2007.

Senado Federal. Disponível em: <www.senado.gov.br>. Acesso em: 22 maio 2007.

. Senado Federal. Disponível em: <http://www.tiaoviana.com/index.php? $\overline{\text { option}=c o m \_c o n t e n t \& t a s k=b l o g c a t e g o r y \& i d=15 \& I t e m i d=34>. ~ P L S ~ n . ~ 121 / 07 . ~}$ Acesso em: 6 out. 2007.

. Senado Federal. Disponível em: <http://www.senado.gov.br/sf/ativi$\overline{\mathrm{dade} / \mathrm{m} a t e r i a / d e t a l h e s . a s p ? p \_c o d \_m a t e}=80262>$. Processo de Tramitação do PLS n. 121/07. Acesso em: 6 out. 2007.

DALLARI, Sueli G. et al. Advocacia em saúde no Brasil contemporâneo. Revista de Saúde Pública, São Paulo, v. 30, n. 6, p. 592-601, 1996.

ESCOREL,Sarah; NASCIMENTO, Dilene R.; EDLER, Flavio C. As origens da reforma sanitária e do SUS. In: SAÚDE e democracia: história e perspectivas do SUS. Rio de Janeiro: Fiocruz, 2005. p. 59-81.

FAVERET, Ana C. S. C. A vinculação constitucional de recursos para a saúde: avanços, entraves e perspectivas. Revista Ciência \& Saúde Coletiva, Rio de Janeiro, v. 8 n. 2, p. 371-378, 2003.

GOMES, Maria Angélica. Equidade e universalidade do direito à saúde: representação de interesses no Congresso Nacional, 1987-1990. Dissertação (Mestrado) - Faculdade de Estudos Sociais Aplicados, Universidade de Brasília, 1996. Mimeo.

KHAN, A. J.; KAMERMAN, S. B.; MAC, G.; BRENDA, G. Child advocacy: report of a national baseline study. DITEW Publication N. O. (OCD), n. 73-18, p. 7-95.

LAZZARI, J. B. Fontes de financiamento do Sistema Único de Saúde. Revista de Direito Sanitário, São Paulo, v. 4, n. 1, p. 75-84, mar. 2003.

REIS, Carlos Octávio O.; RIBEIRO, José Aparecido c.; PIOLA, Sergio F. Financiamento das políticas sociais nos anos 1990: o caso do Ministério da Saúde. Brasília: IPEA, 2001.

SAMBIASE, A. G. F. Aspectos legais da Emenda Constitucional n. 29/00. Revista de Direito Sanitário, São Paulo, v. 4, n. 1, p. 63-74, mar. 2003. 